\title{
An Investigation Approach on the Sequestration of Divalent Metal lons Employing Animal Waste
}

\author{
N.S. GAYATHRI ${ }^{1}$, N. MUTHULAKSHMI ANDAL ${ }^{2 *}$ and J. ANURADHA ${ }^{3}$ \\ 2*Assistant Professor Department of Chemistry, PSGR Krishnammal College \\ for Women, Coimbatore, India. \\ ${ }^{1,3}$ Research Scholars Department of Chemistry, PSGR Krishnammal College \\ for Women, Coimbatore, India. \\ ${ }^{*}$ Corresponding Author Email:muthulakshmiandal @ psgrkc.ac.in
}

http://dx.doi.org/10.13005/ojc/330342

(Received: March 04, 2017; Accepted: April 23, 2017)

\begin{abstract}
The current investigation deals with utilizing Treated Goat Hoof (TGH), a no cost material derived from butcher shop for the removal of $\mathrm{Pb}$ (II) and $\mathrm{Cd}$ (II) ions from aqueous media. FTIR / SEM analyses are carried out for the functional groups identification and describe the surface morphology of the chosen material respectively. Batch studies are experimented under varied operating factors viz., particle size, dosage, initial concentration, contact time and $\mathrm{pH}$ of the medium to assess the sorptive nature of the chosen material. Verification of the experimental data reveal the optimized conditions for the uptake of $\mathrm{Pb}(\mathrm{II})$ and $\mathrm{Cd}(\mathrm{II})$ by $\mathrm{TGH}$. Langmuir model registered the best linearity amongst the isothermal plots derived for Langmuir, Freundlich and Tempkin models. Experimental results of both the systems: $\mathrm{Pb}(\mathrm{II})-\mathrm{TGH}$ and $\mathrm{Cd}(\mathrm{II})-\mathrm{TGH}$ are subjected to Statistical tool analyses using SPSS 20 software for significance and correlation assessment.
\end{abstract}

Keywords: goat hoof, isotherms, optimization, statistics.

\section{INTRODUCTION}

Water is essential for the very existence of life. Rapid industrialization is the major cause for heavy metal laden discharges into aqueous streams which are declared as toxic pollutants beyond the tolerance level. ${ }^{1}$ The chronic toxicity of heavy metals is due to the property that most of it salts are soluble in water. ${ }^{2}$ Environmental concerns have motivated many methods for heavy metal removal. Most commonly employed methods include chemical precipitation, ion exchange, adsorption, electro coagulation, membrane filtration and reverse osmosis. These techniques however, have their own disadvantages such as incomplete metal removal, high reagent/ energy requirements, generation of toxic sludge and setting up of the experimental scale. $^{3}$

Adsorption method is found to be more effective in sequestering heavy metal ions from aqueous solutions ${ }^{4}$ and wastewaters. ${ }^{5}$ Goat Hoof, a 
litter pollutant is employed in the present study where reports have not been found elsewhere in literature using this material for the heavy metal removal. The employment of Lead and cadmium ions in varied industries located in Coimbatore such as paper/ pulp $^{6}$, electroplating, metal finishing and batteries ${ }^{7}$ have been the reason for has led to the basis for the choice of these metals to study.

\section{MATERIALS AND METHODS}

\section{Adsorbent Preparation}

Goat Hoof $(\mathrm{GH})$ were collected in bulk, from the butcher shops located at market places in Coimbatore, washed well with distilled water broken to smaller pieces, sun dried for a week, soaked in $0.2 \mathrm{~N}$ Sodium Hydroxide for 3 hours and the $\mathrm{pH}$ was adjusted to 9. The Treated Goat Hoof (TGH) were then dried, pulverized in a laboratory blender, sieved into different particle sizes viz., 22 BSS $(0.71 \mathrm{~mm})$, 36 BSS $(0.42 \mathrm{~mm}), 52 \mathrm{BSS}(0.30 \mathrm{~mm}), 72 \mathrm{BSS}(0.21$ $\mathrm{mm})$ and $85 \mathrm{BSS}(0.18 \mathrm{~mm})$ using standard Scientific Test Molecular Sieves. The pictorial representations of the purchased, sieved Goat Hoof $(0.18 \mathrm{~mm})$ are shown in fig 1a \& $1 \mathrm{~b}$ and the microscopic view of $0.18 \mathrm{~mm}$ size of $\mathrm{TGH}$ is depicted in fig $1 \mathrm{c}$.

\section{Adsorbate Solution}

Stock solutions with a concentration of 1000 $\mathrm{mg} / \mathrm{L}$ of $\mathrm{Pb}(\mathrm{II})$ and $\mathrm{Cd}(\mathrm{II})$ were prepared using Lead Nitrate and Cadmium Acetate (AR Grade, MERCK) salts respectively. All working standard solutions of various concentrations were prepared by appropriate dilutions of the stock solution.

\section{Batch Equilibration Experiments}

Experiments of $\mathrm{Pb}(\mathrm{II})$ and $\mathrm{Cd}(\mathrm{II})$ systems using TGH were carried out in order to assess its sorption efficiency, through the role of variable parameters viz., particle sizes $(0.18 \mathrm{~mm}-0.71 \mathrm{~mm})$ and dosages(50 mg- $250 \mathrm{mg}$ : $50 \mathrm{mg}$ ) of TGH, initial concentrations $(50,100,150,200$ and $250 \mathrm{mg} / \mathrm{L})$ of the divalent solutions, agitation time between the sorbate and sorbent species (5 - $30 \mathrm{~min}: 5 \mathrm{~min}$ ) and $\mathrm{pH}$ of the medium (3, 5, 7, 9 and 11). $50 \mathrm{ml}$ of the predetermined concentrations of $\mathrm{Pb}(\mathrm{II})$ and $\mathrm{Cd}(\mathrm{II})$ were taken in $100 \mathrm{ml}$ Erlenmeyer flasks and appropriate doses of $\mathrm{TGH}$ with specified sizes $(\mathrm{pH}$ of sorbent maintained at 9 after various trails) were added and agitated in a Rotary Shaker (KEMI) at $120 \mathrm{rpm} /$ minute for preset time intervals, the temperature being $30^{\circ} \mathrm{C}$. The $\mathrm{pH}$ measurements of the sorbent, unloaded, loaded samples were recorded using LABTRONICS $\mathrm{pH}$ meter. The initial and residual metal ion concentrations of the chosen divalent ions were analyzed using SHIMADZU (AA 6200) Atomic Absorption Spectrophotometer (AAS) operated with air acetylene flame. The concentrations of the unknown samples were observed as a linear range of the references with dilutions to appropriate concentrations.

The percentage adsorption of metal ions was estimated using the following equation. ${ }^{8}$

$\%$ adsorption $=\left(C_{i}-C_{e}\right) / C_{i} \times 100$

The amount of sorbate species adsorbed (q)

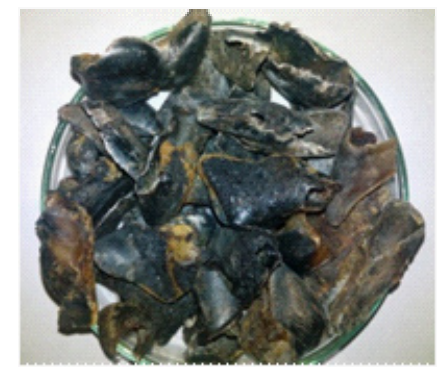

Fig. 1a: Purchased Goat Hoof

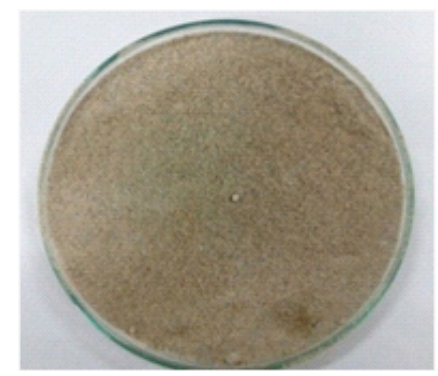

Fig. 1b: Sieved Goat Hoof -0.18 mm

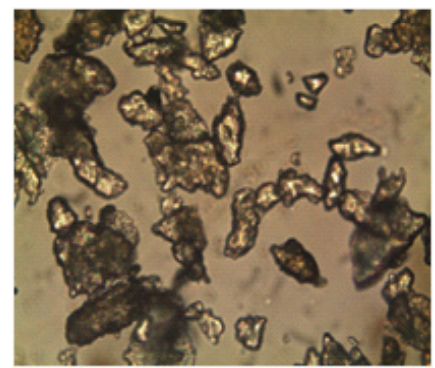

Fig. 1c: Microscopic image of TGH 
were calculated using the following mass balance equation

$q=V\left(C_{i}-C_{e}\right) / W$

where, $\mathrm{V}$ is the volume of the solution ( $\mathrm{L})$, $\mathrm{W}$ is the mass of the adsorbent $(\mathrm{g}), \mathrm{C}_{i}$ and $\mathrm{C}_{e}$ are the initial and equilibrium metal concentrations $(\mathrm{mg} / \mathrm{L})$ respectively.

\section{Statistical Analysis}

The Batch Equilibration results were systematically analyzed using SPSS 20 (IBM SPSS Statistics) Software. Studies on Descriptive, paired $T$ test and analysis of variance (ANOVA) were

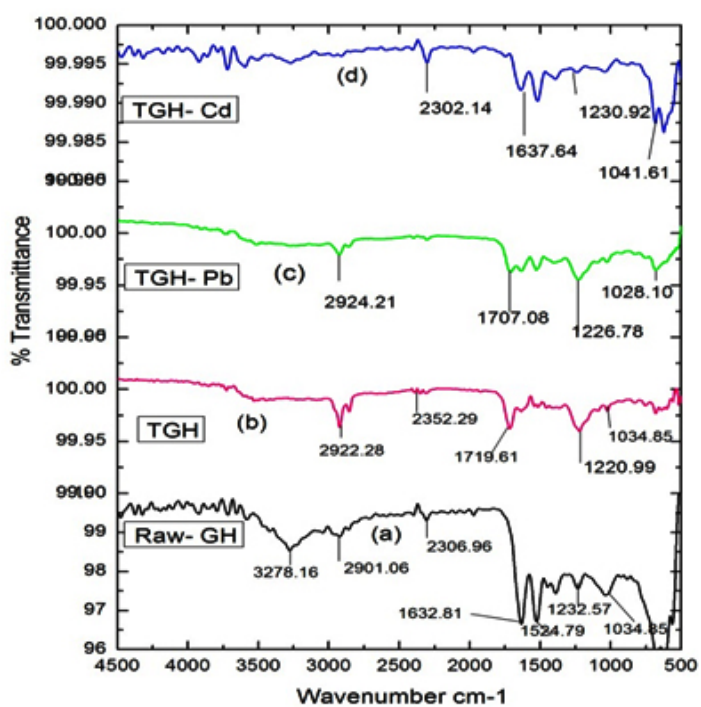

Fig. 2: FT-IR spectra of $\quad$ (a) raw GH $\quad$ (b) TGH (c) $\mathrm{Pb}$ (II) - TGH (d) Cd(II) - TGH calculated to validate the experimental data for the effects of optimized particle size, dosage, $\mathrm{pH}$, initial concentration and contact time during the adsorption process. These tests were used to compare the relationship and variability of the parametric data where the significance is based on $95 \%$ confidence level.

\section{RESULTS AND DISCUSSION}

\section{Physicochemical Characteristics - TGH}

Table 1 lists the physicochemical characteristics of $\mathrm{TGH}$, as compared with that of other studied sorbents. The specific gravity was observed to lie between 1.3 and 2.0, implying the inactiveness of the organic material during sorption process. The bulk density value $<1$ is indicative of large number of pores on the TGH surface, inturn supporting the enhanced metal sorption. The porosity value (53.305) specifies the fact that the chosen material is mesoporous in nature, defining it to possess excellent sorption capacity against other compared values. The ash content value of TGH (4.1805) indicates the larger percent of carbon content and least presence of inorganic matter. Moisture content $(<5 \%)$ indicates of favorable adsorption. The lower ash and moisture content values promote the advantageous sorptive nature of the TGH which is observed to be greater than in the corresponding values (table 1). Therefore, the trapping ability of TGH may be highly dependent on its chemical nature and internal pore structure.

\section{FT-IR Analysis}

The possibilities of functional groups on $\mathrm{TGH}$ to be involved in the biosorption of $\mathrm{Pb}(\mathrm{II})$

Table 1: Characteristics Comparison with other sorbents

\begin{tabular}{|c|c|c|c|c|}
\hline Factors & Goat Hoof & Prosopis Spicigera ${ }^{9}$ & Feronialimonia Shell ${ }^{10}$ & $\begin{array}{l}\text { Ricinuscommunis } \\
\text { Seed Shell }{ }^{11}\end{array}$ \\
\hline $\mathrm{pH}$ & 8.24 & 6.9 & 6 & 7.7 \\
\hline $\begin{array}{l}\text { Bulk } \\
\text { density } \\
\text { (g/L) }\end{array}$ & 0.61 & 0.3915 & 0.757 & 0.4384 \\
\hline Specific gravity & 1.304 & 1.48 & 1.49 & 1.6367 \\
\hline Porosity & 53.3052 & 70 & 49.19 & 70 \\
\hline Moisture (\%) & 2.24 & 8.5 & 17.2 & 3 \\
\hline $\begin{array}{l}\text { Ash } \\
\text { content } \\
(\%)\end{array}$ & 4.1805 & 3.86 & 10.16 & 7.52 \\
\hline
\end{tabular}


and $\mathrm{Cd}(\mathrm{II})$ ions were determined using FT-IR Spectroscopic studies (fig 2). The major functional groups observed on the raw $\mathrm{GH}$ fig 2(a) with their corresponding peaks are $\mathrm{O}-\mathrm{H}\left(3278.16 \mathrm{~cm}^{-1}\right)$, $\mathrm{C}-\mathrm{H}\left(2901.06 \mathrm{~cm}^{-1}\right), \mathrm{C}=\mathrm{O}\left(1632.81 \mathrm{~cm}^{-1}\right)$, S-H $\left(2306.96 \mathrm{~cm}^{-1}\right)$, C-O $\left(1232.57 \mathrm{~cm}^{-1}\right.$ and $\left.1034.85 \mathrm{~cm}^{-1}\right)$ and amino group (1524.79 $\mathrm{cm}^{-1}$ and $1389.77 \mathrm{~cm}^{-1}$ ). The $\mathrm{OH}$ band at $3278.16 \mathrm{~cm}^{-1}$ is found to disappear after treatment, indicating the deprotonation, followed by the probable formation of metal oxygen bond during sorption. A shift in the position of few functional groups is noticed in the unloaded and metal laden TGH supporting the involvement of these groups during sorption process.

\section{Surface Morphology}

The SEM images of the unloaded and metal laden $\mathrm{TGH}$ depicted in figs $3 \mathrm{a}, 3 \mathrm{~b} \& 3 \mathrm{c}$. Fig $3 a$ registers a high porous morphology and a coarse surface texture with different shapes and sizes. The morphological changes as obvious from fig $3 b$ \& $3 c$ suggest that effective sorption of $\mathrm{Pb}(\mathrm{II})$ and $\mathrm{Cd}(\mathrm{II})$ had occurred on the sorbent's surface.

\section{Effect of Particle Size}

Particle size plays a vital role in the determining the sequestration capacity of TGH for the uptake of $\mathrm{Pb}$ (II) and $\mathrm{Cd}$ (II) from aqueous solutions. Both the systems registered a maximum sorption capacity $(\mathrm{mg} / \mathrm{g})$ against smallest the particle size of $0.18 \mathrm{~mm}$ amongst the chosen sizes (fig 4). This can be explained by the fact that relatively smaller particle size yields large surface area. According to Weber and Morris ${ }^{12}$, the breaking of larger particles tends to open tiny cracks and channels on the particle size surface of the material resulting in more accessibility towards better diffusion.

\section{Effect of $\mathrm{pH}$}

The results pertaining to variable $\mathrm{pH}$ environments for the studied metal systems are represented in fig 5.Adsorption is observed to increase with $\mathrm{pH}$ and the maximum amount adsorbed were recorded at $\mathrm{pH} 5$ \& $\mathrm{pH} 7$ for $\mathrm{Pb}$ (II) and $\mathrm{Cd}(\mathrm{II})$ ions respectively. Further increase in $\mathrm{pH}$ led to a decline in the adsorption curves. The reduced sorption rate at highly acidic and alkaline $\mathrm{pH}$ ranges may be attributed to the protonation of the sorption sites and

Table 2: Descriptive, T- Test and ANOVA analysis of various parameters

\begin{tabular}{|c|c|c|c|c|c|c|c|c|c|}
\hline \multirow[t]{2}{*}{ System } & \multirow[t]{2}{*}{ Parameter } & \multicolumn{2}{|c|}{ Descriptive } & \multirow[b]{2}{*}{ SEM } & \multirow[b]{2}{*}{$\mathbf{P}$} & \multicolumn{2}{|c|}{ Paired T-Test } & \multirow{2}{*}{$\begin{array}{c}\text { ANOVA } \\
\text { MS }\end{array}$} & \multirow[b]{2}{*}{ ss } \\
\hline & & Mean & SD & & & Corr. & Sig. & & \\
\hline $\mathrm{Pb}(\mathrm{II})-$ & Particle Size & 22.47 & 3.07 & 1.37 & 0.03 & -0.94 & 0.01 & 37.77 & 9.44 \\
\hline \multirow[t]{3}{*}{$\mathrm{TGH}$} & Dosage & 22.07 & 4.01 & 1.79 & 0.09 & 0.91 & 0.03 & 64.18 & 16.05 \\
\hline & $\begin{array}{l}\text { Initial conc. } \\
\& \text { contact time }\end{array}$ & 22.01 & 4.44 & 2.22 & 0.04 & 0.45 & 0.54 & 59.37 & 19.79 \\
\hline & $\mathrm{pH}$ & 22.56 & 2.89 & 1.29 & 0.02 & -0.41 & 0.48 & 33.54 & 8.38 \\
\hline $\mathrm{Cd}(\mathrm{II})-$ & Particle Size & 24.57 & 2.38 & 1.06 & 0.04 & -0.95 & 0.01 & 22.74 & 5.68 \\
\hline \multirow[t]{3}{*}{$\mathrm{TGH}$} & Dosage & 23.60 & 3.22 & 1.44 & 0.06 & 0.22 & 0.72 & 41.53 & 10.38 \\
\hline & $\begin{array}{l}\text { Initial conc. } \\
\& \text { contact time }\end{array}$ & 22.74 & 5.02 & 2.51 & 0.04 & 0.36 & 0.63 & 75.75 & 25.25 \\
\hline & $\mathrm{pH}$ & 23.38 & 2.33 & 1.04 & 0.05 & -0.22 & 0.71 & 21.77 & 5.44 \\
\hline
\end{tabular}

SD - Standard Deviation SEM - Standard Error of Mean Corr. - Correlation

Sig. - Significance MS - Mean Square SS - Sum Square

Table 3:Calculated isothermal constants for $\mathrm{Pb}$ (II) and $\mathrm{Cd}$ (II) on TGH

\begin{tabular}{|c|c|c|c|c|c|c|c|c|c|c|}
\hline \multirow[t]{2}{*}{ System } & \multicolumn{4}{|c|}{ Langmuir } & \multicolumn{3}{|c|}{ Freundlich } & \multicolumn{3}{|c|}{ Tempkin } \\
\hline & $Q_{m}$ & b & $\mathbf{R}^{2}$ & $\mathbf{R L}$ & $K_{f}$ & $1 / n$ & $\mathbf{R}^{2}$ & B & A & $\mathbf{R}^{2}$ \\
\hline $\mathrm{Pb}(\mathrm{II})-\mathrm{TGH}$ & 29.76 & 1.17 & 0.99 & 0.016 & 24.53 & 0.032 & 0.96 & 10.88 & 9.57 & 0.95 \\
\hline $\mathrm{Cd}(\mathrm{II})-\mathrm{TGH}$ & 29.94 & 1.06 & 0.98 & 0.010 & 21.67 & 0.031 & 0.95 & 10.01 & 11.45 & 0.94 \\
\hline
\end{tabular}




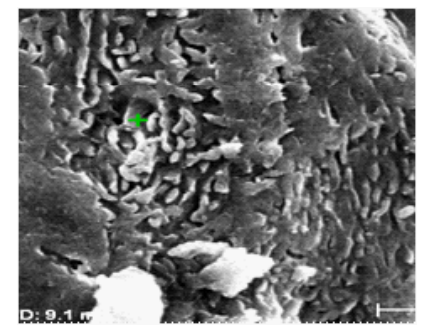

Fig. 3a: SEM image of unloaded TGH

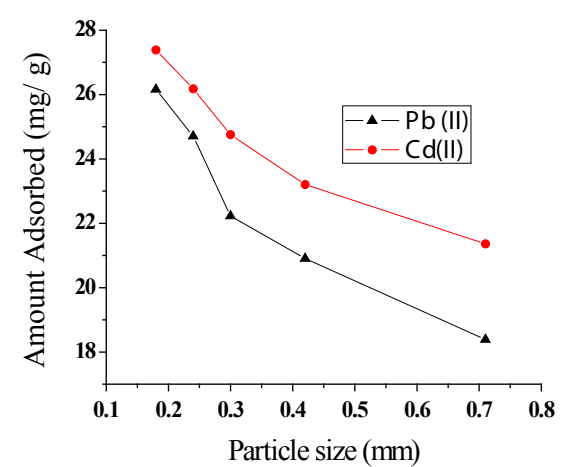

Fig. 4: $\mathrm{Pb}(\mathrm{II}) \& \mathrm{Cd}(\mathrm{II})$ - Particle size

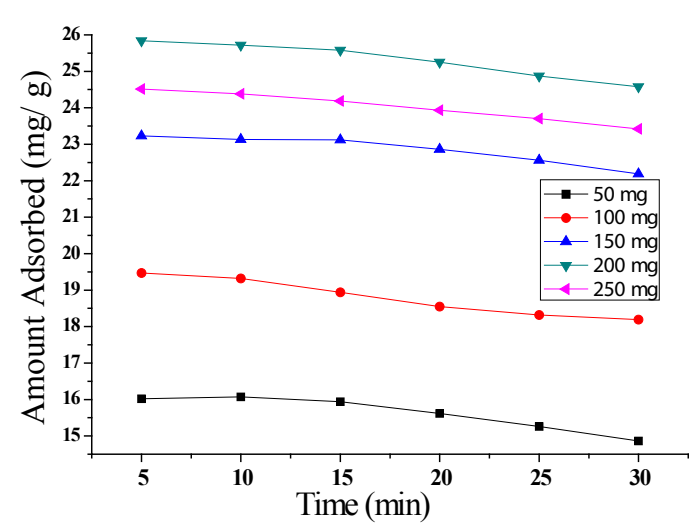

Fig. 6a: $\mathrm{Pb}(\mathrm{II})$ - Dosage

preferential hydroxyl complex formation of the metal ion in solution respectively. ${ }^{13}$

\section{Effect of Adsorbent Dose}

Removal of metal ions were found to be less at lower doses, but exponentially increased and reached equilibrium at $200 \mathrm{mg}$ (figs $6 \mathrm{a} \& 6 \mathrm{~b}$ ). The increase in metal uptake against doses $(50-200$ $\mathrm{mg}: 50 \mathrm{mg}$ ) is due to the proportional availability of active sites for adsorption. ${ }^{14,15}$

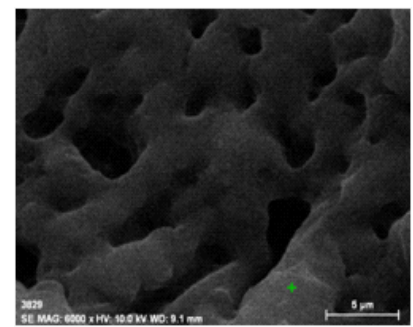

Fig. 3c: SEM image of Cd(II) - TGH

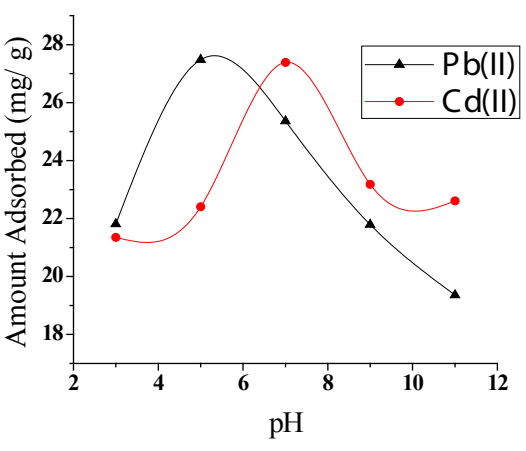

Fig. 5: $\mathrm{Pb}$ (II) \& $\mathrm{Cd}(\mathrm{II})-\mathrm{pH}$

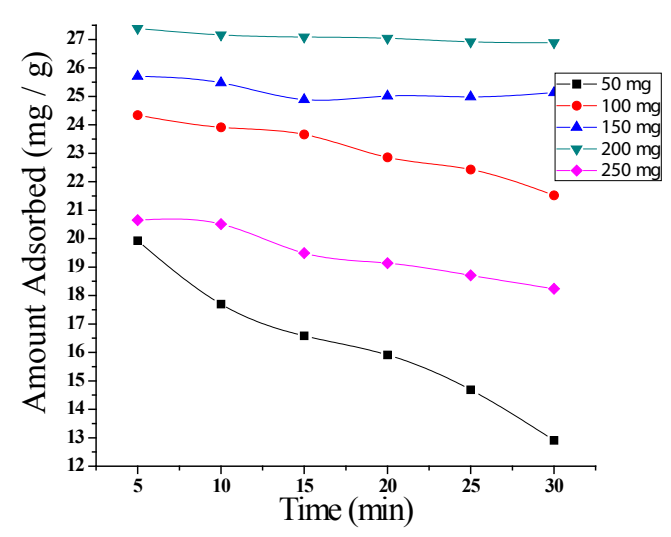

Fig. 6b: $C d(I I)-$ Dosage

\section{Effect of Initial Concentration and Contact} Time

The influences of initial metal ion concentration ( $50-200 \mathrm{mg} / \mathrm{L}: 50 \mathrm{mg} / \mathrm{L})$ and contact time (5 - 10 mins : 5 mins) for $\mathrm{Pb}(\mathrm{II})-\mathrm{TGH}$ and $\mathrm{Cd}(\mathrm{II})$ - TGH systems are presented in figs $7 \mathrm{a} \& 7 \mathrm{~b}$ respectively. Equilibrium was found to attain at a contact time of 5 minutes after which the systems appeared to reach a saturation point. This is obvious from the plateau nature of the curves from $5-30$ mins. Increase in percent removal against metal ion 
concentration (upto $100 \mathrm{mg} / \mathrm{L}$ ) is obvious from the figures. Further increase in initial concentration leads to the lowering of metal up take, the reason could be reduction in ratio of sorptive surface to metal ion concentration. Henceforth, $100 \mathrm{mg} / \mathrm{L}$ was fixed as the optimum concentration for both the systems with an agitation time interval of 5 mins for their removal.

\section{Interpretation of SPSS}

Based on the results and observations, conditions have been optimized for the maximum

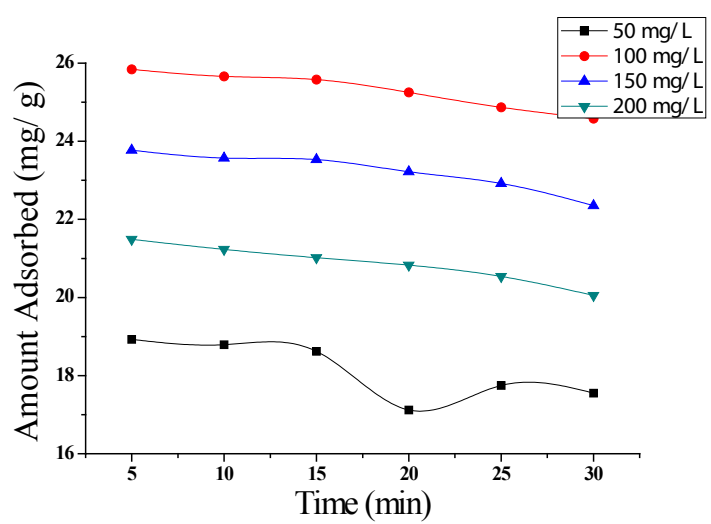

Fig. 7a: $\mathrm{Pb}(\mathrm{II})$ - Initial Concentration and Contact Time

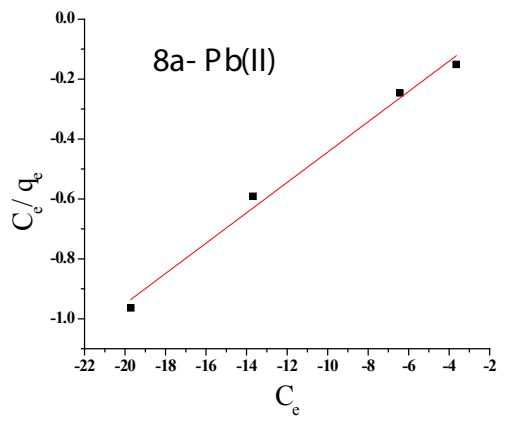

Fig. 8a: Langmuir Plot - Pb(II)

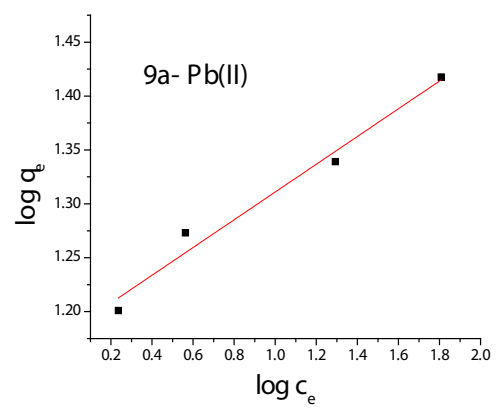

Fig. 9a: Freundlich Plot - Pb(II) removal as: $0.18 \mathrm{~mm}$ Particle Size, $200 \mathrm{mg}$ Dose, 5 mins Contact Time, $100 \mathrm{mg} / \mathrm{L}$ Initial Concentration for both the systems with variation in fixation of $\mathrm{pH}$ ranges $[\mathrm{pH} 5$ for $\mathrm{Pb}(\mathrm{II})]$ and $[\mathrm{pH} 7$ for $\mathrm{Cd}(\mathrm{II})]$. The statistical criteria used to corroborate the optimized experimental data on the adsorption process of the systems are listed in table 2. Mean value, Standard deviation value, Standard error of mean value and $P$ values were calculated with reference to the significant value of 0.05 confidence level. Paired T-test registered the significant correlation between

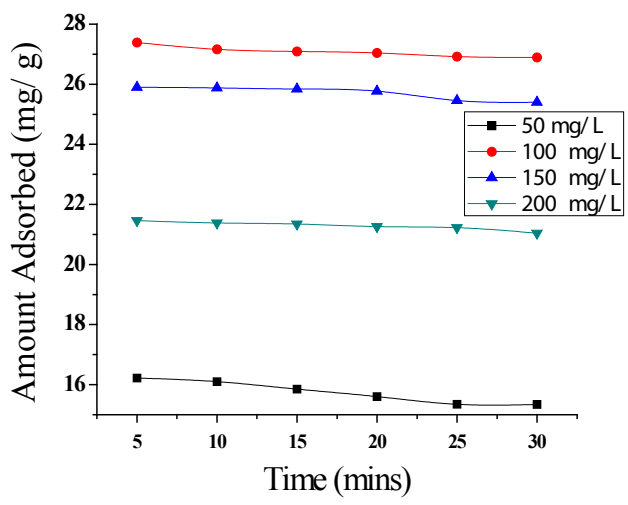

Fig. 7b: $\mathbf{C d}(\mathrm{II})$ - Initial Concentration and Contact Time

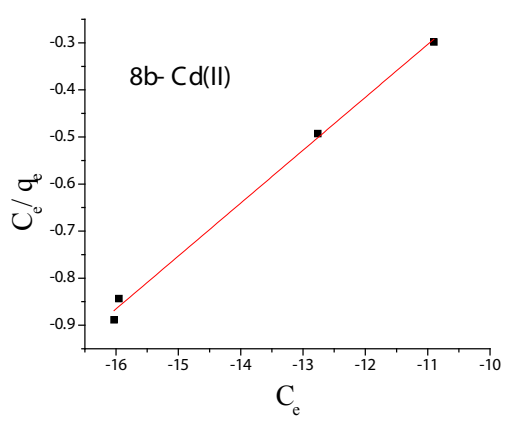

Fig. 8b: Langmuir Plot - Cd(II)

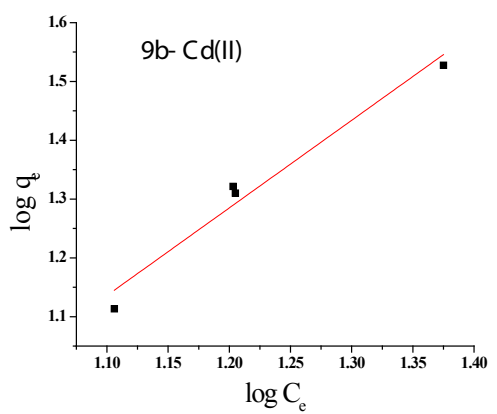

Fig. 9b: Freundlich Plot - Cd(II) 
the amounts of divalent ions adsorbed $\left(q_{e} \mathrm{mg} / \mathrm{g}\right)$ and relevant assessed parameters. The mean square and sum square values of ANOVA calculated intend to signify the deviation between the sorbed and un adsorbed species. The calculated statistical data are found to correlate well with the experimental data.

The probability values calculated for the influence of operating parameters viz., particle size, initial concentration and contact time, $\mathrm{pH}$ are observed to be lesser than the significant value (0.05), implying of the rejection of null hypothesis for both the metal ions. But in the case of dosage, the $P$ values are greater than the significant value (0.05), favoring the acceptability of null hypothesis.

From the T- test results, a negative correlation is observed for the study of particle size and $\mathrm{pH}$ factors, representing an increase in the sorption, being indirectly proportional to the aforesaid factors. The positive correlation values from the calculations as far as the effects of dosage, initial concentration and contact time are concerned, indicate an increase in the amount adsorbed with an inclination of the parametric values for both the systems.

Sum square and Mean square values of each factor quantifies their importance in the adsorption process where these values play a significant role in favour of the experimental evidences.

\section{Adsorption Isotherm}

Adsorption isotherms indicate the distribution of molecules between the liquid phase and solid phase when the adsorption process reaches an equilibrium state. ${ }^{17}$ The present study focuses on three isothermal studies viz., Langmuir,

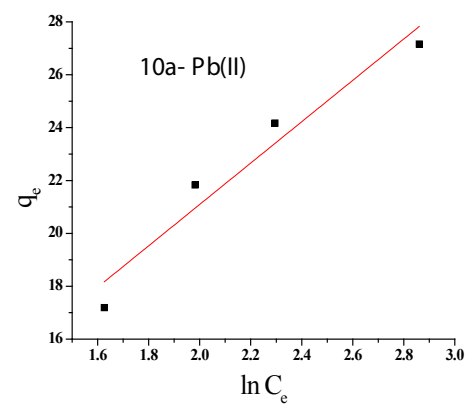

Fig. 10a: Tempkin Plot - Pb(II)
Freundlich and Tempkin, where isothermal constant values are tabulated in table 3.

\section{Langmuir Isotherm}

Langmuir Isotherm equation can be written as

$C_{e} / Q_{e}=C_{e} / Q_{m}+1 / b Q_{m}$

The Langmuir constants $Q_{m}$ and $b$ of $\mathrm{Pb}(\mathrm{II})-\mathrm{TGH}$ and $\mathrm{Cd}(\mathrm{II})$ - TGH were calculated from the linear slopes $1 / Q_{m}$ and intercepts $1 / b Q_{m}$ from the figs $8 a$ and $8 b$, is listed in table 3. Maximum $\mathrm{Q}_{\mathrm{m}}$ values of $\mathrm{Pb}(\mathrm{II})-\mathrm{TGH}$ and $\mathrm{Cd}(\mathrm{II})-\mathrm{TGH}$ systems being $29.7619 \mathrm{mg} / \mathrm{g}$ and $29.9401 \mathrm{mg} / \mathrm{g}$ respectively, indicate the physical monolayer adsorption. The essential characteristics of the Langmuir equation can be expressed in terms of a dimensionless separation factor $\left(R_{L}\right)$. The $R_{L}$ values implyanun favourableadsorption $\left(R_{L}>1\right)$, Linear $\left(R_{L}=1\right)$, favourable $\left(0<R_{L}<1\right)$, or irreversible $\left(R_{L}=0\right)$. $R_{L}$ values for the current study lying between 0 and 1 declare favourable adsorption under specified conditions. ${ }^{18}$ The correlation coefficients $\left(R^{2}\right)$ ranging as 0.9994 and 0.9997 for $\mathrm{Pb}$ (II) and $\mathrm{Cd}(\mathrm{II})$ ions with best linear fit of the plot favour Langmuir isotherm.

\section{Freundlich isotherm}

Linear plots of $\log C_{e} V s_{e}$ (figs $9 a$ and $9 \mathrm{~b}$ ) based on the Freundlich equation: $\left(\log q_{e}=\log K_{f}+1 / n \log C_{e}\right)$, indicate that the systems obey this isotherm model also. However, a comparison amongst the isothermal constants reveals the better fit of Langmuir model. This is further supported by the adsorption intensity values (b $>1 / n)$.

\section{Tempkin isotherm}

Tempkin isothermal equation $\left(q_{e}=B \ln A+B \ln C_{e}\right)$ contains a factor that explicitly takes into account adsorbent-adsorbate interactions.

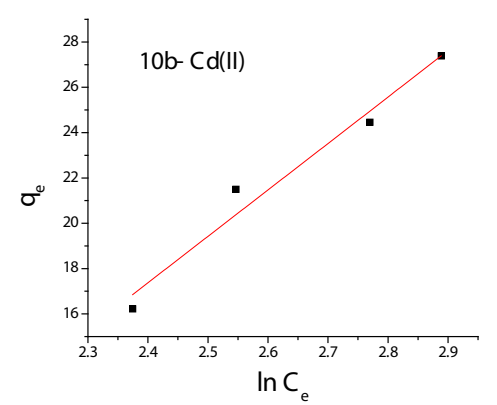

Fig. 10b: Tempkin Plot - Cd(II) 
The constant $A$ and $B$ are related to the heat of sorption and maximum binding energy respectively (figs $10 \mathrm{a} \& 10 \mathrm{~b}$ ). The values of correlation coefficients and constants fairly fitted to the Temkin model and the results were similar to those of M. Sujatha et al. ${ }^{19}$

\section{CONCLUSION}

Goat hoof, an animal waste were collected from local butchers were employed for the removal of toxic $\mathrm{Pb}(\mathrm{II})$ and $\mathrm{Cd}(\mathrm{II})$ ions from aqueous solutions, with seldom research reported elsewhere. The collected was subjected to chemical treatment and the sample was tested for its suitability to remove the chosen divalent ions by Batch Equilibration method. This was ensured through the verification of operational factors and further confirmed by characteristics (FTIR \& SEM) and Statistical analyses (Descriptive, T-Test \& ANOVA). Isothermal studies proved the better linear fit in of Langmiur plot, thereby supporting mono layer adsorption. Based on these observations, it is concluded that Treated Goat Hoof serves the betterment of the societal setup as a part of cleaning up the litter and trapping the toxic ions with $98 \%$.

\section{REFERENCE}

1. Mehmet Emin Argun; Sukru Dursun; Mustafa Karatas. Desal. 2008, 249, 519-527.

2. Dhiraj Sud; Garima Mahajan; Kaur,M.P. Biores Technol. 2008, 99, 6017-6027.

3. Ahalya, N.; Kanamadiand, R.D.;Ramachandra, T.V.J. Environ. Biol,2007, 28(4): 765-769.

4. Boldizsar Nagy .; Carm e n Mânzatu;SzendeTonk.; and Cornelia Majdik.J. Environ. \& Biotech. Res.2016,2(1),27-36.

5. Ahmaruzzaman, M.Adv. Colloid Interface Sci.2011, 166, 36-59.

6. Verma, V. K.; Gupta, R. K.; and Rai, J. P. N. J. Sci\& Indus Res, 2005, 64, 778- 781.

7. Wan Ngah, W.S.; Hanafiah, M.A.K.M. Biores. Technol.2008, 99, 3935-3948.

8. Venkateswaran, V.; Kalaamani, P.; and Karpagam,N.Chem. Sci. Trans.2015, 4(2),347354.

9. Karthikeyan, S.; Sivakumar,P. J. Environ. \& Nanotech.2012, 1(1): 05-12.

10. Thamilarasu, P.;and Karunakaran, K. Can. J. Chem. Eng. 2012,9999, 1-10.

11. Javier Bayo,Chem. Eng. J. 2012,191, 278287.
12. Karthikeyan, S.; Sivakumar, P.; and Palanisamy, P. N.E - J. Chem. 2008,5, 409426.

13. Nwabanne, J.T.; and Igbokwe, P.K.Int. J. Multidisplinary Sci. Eng.2012, 3(7), 46- 52.

14. Leila Mahdavian.Afr. J. o. Microb. Res.2012, 6(1), 183-189.

15. JeyaseelanAravind; Shanmugaprakash Muthusamy; Sangeetha Hubbathalai Sunderraj; Lenin Chandran; Kanmani Palanisamy. Int. J. Indus. Chem. 2010, 2(2), 72-82.

16. Hossain, M. A.; Ngo, H. H.;Guo, W. S.; and Nguyen, T. V. J. Water Sustain. 2012, 2(1), 87-104.

17. AhmetOrnek; Mahmut Ozacar; AyhanSengil, I.Biochem. Eng J. 2007, 37, 192-200.

18. $\mathrm{H}$ a n i m A w a b ; a n d ThanalechumiParamalinggam.J. Fund. Sci. 2011, 7(2), 113-119.

19. Sujatha, M.; Geeetha, A.; Sivakumar, P.; Palanisamy, P.N.E- J. Chem. 2008, 5(4), 742753. 